\title{
Tall Teeth for Geophagy
}

\author{
Hypsodonty in Mammals: Evolution, Geomorphology, and the Role of Earth Surface \\ Processes. Richard H. Madden. Cambridge: Cambridge University Press. 2015. 443 pp., \\ US\$134.00 (Hardback). ISBN 9781107012936
}

\author{
Brian Lee Beatty ${ }^{1}$
}

Published online: 18 November 2016

(C) Springer Science+Business Media New York 2016

Mammal paleontology has relied on data inferred from tooth morphology as dietary indicators for many years. This is rightly so, as our experience shows us that most mammals utilize their teeth to manipulate and comminute food items to increase surface area and ease digestion. Among the more striking features of mammal dental evolution is the tendency for teeth to become more high-crowned (hypsodonty). This appears to be linked to a need to extend the wear life of an animal's tooth, presumably either because the tooth needs to last longer (longer lifespan of the individual or at least the timeline of tooth usage, "wear life") or to deal with exposure to more abrasives. Less attention has been paid to the role of hypsodonty in correlation with lifespan or wear life, and much more has been paid to what this indicates about the abrasive nature of the diet of hypsodont animals. Due to the default association of dental morphology with diet, hypsodonty has largely been connected to assumptions about food items being the sole source of these abrasives. Thanks to Madden's new book, "Hypsodonty in Mammals," we have a fresh new look at the sources of abrasives that cause dental wear and what this tells us about ecology. Despite the initial studies of dental wear being focused on the role of soil in sheep diets (which are eloquently and thoroughly covered in Madden's book), many years of research of dental microwear has assumed largely that phytoliths found within the leaves of specific plant tissues were the cause of wear, and hence the need for hypsodonty. Numerous studies over the past $10-15$ years have focused on

Brian Lee Beatty

bbeatty@nyit.edu

1 Department of Anatomy, NYIT College of Osteopathic Medicine, Old Westbury, NY 11568, USA debating that assumption, including studies of the material hardness of phytoliths, abiogenic abrasives, and dental tissues as well as experimental studies with animal models being fed diets with varying amounts of biogenic and abiogenic abrasives. Despite this, the current literature continues to often treat this as an either/or argument, usually in systems that imperfectly mimic real life scenarios in an effort to control variables or avoid testing assumptions.

Rich Madden has provided us with an abundance of evidence here that summarily makes the phytolith assumption dead. Through many case studies and reviews of carefully done studies of correlation and causation (for more on that, see the final chapter that muses on the nature of those two epistemological concerns), Madden has made it an essential concern for those doing research on dental wear to consider the environmental context, including the composition of and access to naturally occurring abrasives, as part of their assumptions of what causes wear. Initially spurred by the precocious hypsodonty of South American ungulates, Madden has collected, analyzed, and delivered here study after study that accounts for the role of volcanic and other environmental sources of abrasives that are very likely to act as the third body in the tribological event of indentation and plastic deformation of teeth for animals that chew their food. Much of the data included in this book is not published elsewhere, making this a primary source. Though I would have preferred that all of the content would have gone through a more clearly defined peer review process than is often used in publishing books, I have no doubts about the rigors of those that reviewed it and Madden's own scientific rigor. The outcome of having this all in one place makes it much easier to access and, I hope, will end the era of unstated and untested assumptions about the sources of any abrasives, whether biogenic or not. 